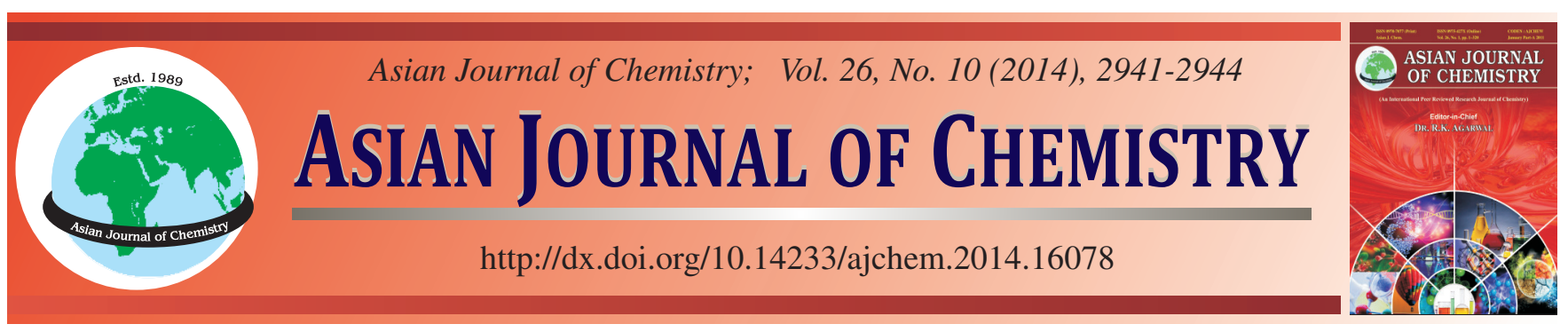

\title{
A Fundamental Study of Amadori Rearrangement Products in Reducing Sugar-Amino Acid Model System by Electrospray Ionization Mass Spectrometry and Computation
}

\author{
Y.F. ZhANG ${ }^{1, \dagger}$, E.D. RUAN ${ }^{2, \dagger, *}$, H. WANG ${ }^{2}$, Y.Y. RUAN ${ }^{3}$, G.J. SHAO ${ }^{1, *}$, J.L. AALHUS ${ }^{2}$ and M. JUÁREZ ${ }^{2}$
}

${ }^{1}$ Hebei Key Laboratory of Applied Chemistry, College of Environmental and Chemical Engineering, Yanshan University, Qinhuangdao 066004, P.R. China

${ }^{2}$ Agriculture and Agri-Food Canada, 6000 C\&E Trail, Lacombe Research Centre, Alberta, T4L 1W1, Canada

${ }^{3}$ Department of Bioengineering, Jilin Agriculture Science and Technology College, Jilin 132101, P.R. China

$\nmid$ These authors have equal contribution

*Corresponding authors: E-mail: Eric.Ruan@ Agr.gc.ca; shaogj@ysu.edu.cn

Received: 20 July 2013;

Accepted: 5 September 2013;

Published online: 10 May 2014;

AJC-15153

\begin{abstract}
It is crucial to characterize Amadori rearrangement products (ARPs) formed in the early stage of Maillard reaction, one of the most important modifications in food science. We setup a reaction model system using six selected amino acids (arginine, asparagines, glutamine, histamine, lysine and tryptophan) and their $\mathrm{N}$-terminal acetylated forms with different reducing sugars for a fundamental study of Amadori rearrangement products. The effects on forming Amadori rearrangement products were studied by using electrospray ionization mass spectrometry (ESI-MS). The reaction rate was affected by reaction temperature, reaction time, property of sugars and amino acids and the fragmentation mechanism of Amadori rearrangement products was illustrated by tandem $\mathrm{MS}\left(\mathrm{MS}^{2}\right)$ with collision-induced dissociation. The proposed fragmentation mechanism of Amadori rearrangement products in $\mathrm{MS}^{2}$ was provided based on $\mathrm{MS}^{2}$ data and it was supported by their computational data of density functional theory (DFT) at the B3LYP/6-31++G(d,p) level.
\end{abstract}

Keywords: Amadori rearrangement products, Maillard reaction, ESI-MS, Density functional theory, Fragmentation.

\section{INTRODUCTION}

Browning of the food has two main types of mechanism, enzymatic and non-enzymatic, depending on whether the process was mediated by enzymes or not. Non-enzymatic reaction, also called Maillard reaction, occurs between reducing carbohydrates with amino acids, peptides and protein moieties and is vital to food science as well as to general biochemistry and even medicine ${ }^{1-3}$. The Maillard reaction follows different routes to produce various final products, through the formation of various complex intermediates ${ }^{4,5}$. Due to the complexity of the reaction, it is still a great challenge to control the reaction for food quality, nutritional value and medicinal aspects. In order to simplify the complex processing of Maillard reaction, it was subdivided roughly into three stages: early stage, intermediate stage and final stage. Early stage includes sugaramine condensation and Amadori rearrangement and the products are colourless. The processing is the nucleophilic of an amine group reacting with the carbonyl group of a reducing sugar to yield a glycosylamine. Glycosylamines are unstable and form $\mathrm{N}$-substituted 1-amino-1-deoxyketoses via an Amadori rearrangement ${ }^{6-8}$. In the intermediate stage, it produces colourless or yellow products via dehydration and fragmentation of sugars and degradation of amino acids, peptides or proteins. A number of reactive species are formed under Amadori rearrangement products degradation in physiological conditions and lead the final stage reaction, forming advanced glycation end products (AGEs) $)^{9,10}$. Due to the importance of Maillard reaction in the field of food and biological science, it has been studied with modern technologies. NMR is the powerful method for identification of Amadori rearrangement products; however, the various tautomers of the ketose moiety in the solution significantly hamper the interpretation of the NMR spectra ${ }^{11}$. Currently, mass spectrometry (MS) related techniques offer an alternative, highly sensitive method and become powerful for the analysis of glycated products in complex mixture. Electrospray ionization mass spectrometry (ESI-MS) has been used to successfully an-alyze some Amadori rearrangement products derived from sugars with proteins in complex system. However, the fragmentation behavior varied in previous reports $^{12-14}$.

In the study, we set up the amino acid-reducing sugar model system for a fundamental study of fragmentation behavior and mechanism of Amadori rearrangement products 
in mass spectra and characterization of the factors affecting the reaction. We illustrate the fragmentation pathways of APRs with combination of computational calculations and it is important for understanding the process of glycosylation between sugars and peptides, even protein in complicated systems.

\section{EXPERIMENTAL}

Sugars and six amino acids: arginine (Arg), asparagines (Asn), glutamine (Gln), histamine (His), lysine (Lys) and tryptophan (Trp), were purchased from Sigma (St. Louis, MO, USA). Water was purified by Milli-Q distilled (Millipore, Bedford, MA, USA). Unless otherwise indicated, all other reagents and solvents were of analytical grade and were purchased from Sigma-Aldrich (St. Louis, MO, USA). The Fmocprotected amino acids and the Wang resin were purchased from Advanced ChemTech., Inc. (Louisville, KY, USA).

Sample preparation: Fmoc-protected amino acid and pre-washed Wang resin mixed with N,N-dimethyl 4-aminopyridine (DMAP) was dissolved in DMF and reacted for $2 \mathrm{~h}$ under nitrogen bubbled at room temperature, then washed DMF (3 times), dichloromethane DCM (3 times) and dried under nitrogen atmosphere. Acetylation of amino acids $1 \mathrm{~mL}$ acetylation reagent (acetic acid:methanol $=1: 4)(\mathrm{v} / \mathrm{v})$ was added to a mixture of Fmoc-protected amino acid with Wang resin $(20 \mathrm{mg})$ and $100 \mathrm{~mL}$ of $50 \mathrm{mM}$ ammonium bicarbonate and stirred for $3 \mathrm{~h}$ at room temperature. Fresh $20 \%$ piperidine in DMF (v/v) was added to the Wang resin with Fmoc-protected amino acid attached at room temperature and swirled for 20 min under nitrogen. The resin was filtered, washed with DMF, DCM and dried under nitrogen gas. Wang resin with acetylated amino acid was cleaved by trifluoroacetic acid (TFA) and filtered. Acetylated amino acid solution was precipitated in tert-butyl methyl ether, purified by HPLC, freeze-dried for experiments.

Maillard reaction model: The reaction model was set as following: $0.1 \mathrm{M}$ of amino acids and acetylated amino acids were dissolved in $1 \mathrm{M} \mathrm{d}$-glucose solution and got the ratio of 1:10 by molecular weight. Freezed-dry by SC250DDA Speedvac Plus (Thermo Electron Corporation, Waltham, MA) the samples to get the whiter power mixture and dry-heating the samples in sealed vials for $1 \mathrm{~h}$ at 50,70 and $90^{\circ} \mathrm{C}$, respectively and cooling down the samples in $-20{ }^{\circ} \mathrm{C}$ immediately after reaction finished. All samples were dissolved with $\mathrm{CH}_{3} \mathrm{CN}$ : $\mathrm{H}_{2} \mathrm{O}$ :FA (40/60/0.5:v/v/v) just before submitting to MS.

Mass spectrometer: All mass spectrometric experiments were conducted using a quadrupole ion trap mass spectrometer, LTQ Deca XP Plus (Finnigan LTQ, Thermo Finnigan, San Jose, CA, USA) equipped with a home-made nanospray ion source. The physical parameters of the interface, i.e. the distance of the needle from the hole in the spray shield (1.2$1.5 \mathrm{~cm})$, the high voltage $(2.8-3 \mathrm{kV})$ added on the stainless steel unit and the temperature of the heated capillary $\left(180^{\circ} \mathrm{C}\right)$, were optimized at the flow rate of $25 \mathrm{~mL} / \mathrm{h}$. Electrospray voltage was typically kept between $2.8-3.0 \mathrm{kV}$ and the inlet capillary was maintained at $180{ }^{\circ} \mathrm{C}$. To obtain the spectra of $\mathrm{MS}^{2}$, the normalized collision energy was varied with all the other ion tuning conditions fixed.

Computational methods: Electronic energies were calculated in the framework of DFT using the unrestricted (U) hybrid functional formulated with a mixture of Hartree-Fock exchange energy and Becke's three-parameter 1988 gradient-corrected exchange energy, as well as Lee-Yang-Parr (LYP) correlation energy $^{15}$. Atomic orbitals were described by a Gaussian-type split valence shell $6-31++\mathrm{G}(\mathrm{d}, \mathrm{p})$ basis set, including polarization and diffuse functions for all atoms ${ }^{16}$. Low-lying structures of the molecular ions were obtained through Monte Carlo conformational searches with a semi-empirical method (AM1) using Spartan software ("SPARTAN, '04 Essential V2.0.0; Wavefunction, Inc.: Irvine, CA, 2004") followed by geometry optimizations at UB3LYP/6-31G(d) and UB3LYP/6-31++G (d,p) levels. Additional DFT geometry optimizations for other plausible low-lying structures, which likely were missed in the conformational searches, also were performed. Harmonic vibrational frequencies of all optimized structures were calculated to confirm the structures were at local minima (all real frequencies). Relative enthalpies at $0 \mathrm{~K}\left(\Delta \mathrm{H}^{\circ}\right)$ were calculated from the electronic energies and zero-point vibrational energies (ZPVE) obtained within the harmonic approximation. All DFT calculations were performed using the Gaussian 03 software package.

\section{RESULTS AND DISCUSSION}

Amino acids, time and sugar effects on Amadori rearrangement products: In our model system, six selected amino acids and their corresponding $\mathrm{N}$-terminal acetylated forms were reacted with three reducing sugars ( $\mathrm{D}$-glucose, $\beta$-lactose and maltose) at 50,70 and $90^{\circ} \mathrm{C}$, respectively. In MS spectra, the main additional masses increased related to intermediates (180 Da; binding with glucose) and to Amadori rearrangement products (162 Da; condensation by loss one molecular of water), compared with mass to charge ratio $(\mathrm{m} / \mathrm{z})$ of the original amino acid in MS spectra (Table-1). Amadori rearrangement products were formed easily for six amino acids and acetylated lysine, it means that reducing sugars preferentially reacted with $\mathrm{N}$ terminal amino group on main chain $\left(\alpha-\mathrm{NH}_{2}\right)$ and of $\varepsilon-\mathrm{NH}_{2}$ on side chain of lysine, but not amino or imine groups on side chain of other five amino acids at studied temperature $(\leq$ $90{ }^{\circ} \mathrm{C}$ ). This demonstrated that reactivity of $\varepsilon-\mathrm{NH}_{2}$ group of lysine is as high as $\alpha-\mathrm{NH}_{2}$ of amino acids with reducing sugars at relative low temperature in Maillard reaction. The results also displayed that extended reaction time increased the yield of Amadori rearrangement products. For example, it took $1 \mathrm{~h}$ to obtain the yield of Amadori rearrangement products (glucosylated lysine) about $50 \%$ at $90{ }^{\circ} \mathrm{C}$, but more than $3 \mathrm{~h}$ at $70{ }^{\circ} \mathrm{C}$ and almost $20 \mathrm{~h}$ at $50{ }^{\circ} \mathrm{C}$ (data not show). All three reducing sugars (D-glucose, $\beta$-lactose and maltose) could react with amino acids noticeably at studied conditions. Among the three reducing sugars, glucose was the most reactive with amino compounds at relatively low temperature $\left(50^{\circ} \mathrm{C}\right)$. The reaction rate of sugars followed the order: glucose $>$ lactose $>$ maltose.

Fragmentation of Amadori rearrangement products in $\mathbf{M S}^{\mathbf{2}}$ : The fragmentation pattern of Amadori rearrangement products in reducing sugar-amino acid model system was systematically studied by ESI-MS ${ }^{2}$ and the MS ${ }^{2}$ spectra of Amadori rearrangement products from D-glucose showed the characteristic fragment ions of $[\mathrm{M}-18+\mathrm{H}]^{+},[\mathrm{M}-36+\mathrm{H}]^{+}$, 


\begin{tabular}{|c|c|c|c|c|c|c|c|c|c|}
\hline \multirow[b]{3}{*}{$\mathrm{AA}^{\mathrm{a}}$} & \multicolumn{9}{|c|}{$\begin{array}{l}\text { TABLE-1 } \\
\text { GLYCATION OF SIX SELECTED AMINO ACIDS AND THEIR CORRESPONDING ACETYLATED AMINO ACIDS } \\
\text { REACTING WITH GLUCOSE, LACTOSE AND MALTOSE UNDER DRY-HEATING AT } 50{ }^{\circ} \mathrm{C}, 70^{\circ} \mathrm{C} \text { AND } 90^{\circ} \mathrm{C}\end{array}$} \\
\hline & \multicolumn{3}{|c|}{ Glucose } & \multicolumn{3}{|c|}{ Lactose } & \multicolumn{3}{|c|}{ Maltose } \\
\hline & $50^{\circ} \mathrm{C}$ & $70^{\circ} \mathrm{C}$ & $90^{\circ} \mathrm{C}$ & $50^{\circ} \mathrm{C}$ & $70^{\circ} \mathrm{C}$ & $90^{\circ} \mathrm{C}$ & $50^{\circ} \mathrm{C}$ & $70^{\circ} \mathrm{C}$ & $90^{\circ} \mathrm{C}$ \\
\hline Arg & $\ddagger$ & $\neq$ & $\ddagger$ & - & - & $\ddagger$ & - & $\dagger$ & $\ddagger$ \\
\hline Asn & $\dagger$ & $\ddagger$ & $\ddagger$ & - & - & $\dagger$ & - & - & $\dagger$ \\
\hline Gln & $\dagger$ & $\dagger$ & $\ddagger$ & - & - & $\dagger$ & - & - & $\dagger$ \\
\hline His & $\dagger$ & $\dagger$ & $\ddagger$ & - & $\dagger$ & $\ddagger$ & - & $\dagger$ & $\ddagger$ \\
\hline Lys & $\ddagger$ & $\ddagger$ & $\ddagger$ & $\dagger$ & $\neq$ & $\ddagger$ & $\dagger$ & $\dagger$ & $\ddagger$ \\
\hline Trp & $\dagger$ & $\dagger$ & $\ddagger$ & - & - & $\dagger$ & - & - & $\dagger$ \\
\hline Ac-arg ${ }^{b}$ & - & - & - & - & - & - & - & - & - \\
\hline Ac-asn & - & - & - & - & - & - & - & - & - \\
\hline Ac-gln & - & - & - & - & - & - & - & - & - \\
\hline Ac-his & - & - & - & - & - & - & - & - & - \\
\hline Ac-lys & $\neq$ & $\neq$ & $\ddagger$ & $\dagger$ & $\ddagger$ & $\ddagger$ & $\dagger$ & $\neq$ & $\ddagger$ \\
\hline Ac-trp & - & - & - & - & - & - & - & - & - \\
\hline
\end{tabular}

${ }^{a} \mathrm{~A}$. A representing Amino acid, ${ }^{\mathrm{b}} \mathrm{Ac}-\mathrm{AA}$ representing N-terminal acetylated amino acid, - Relative intensity of ARPs' peak was $<0.1 \%$, ${ }^{\dagger}$ Relative intensity of ARPs' peak was $>0.1 \%$ and $<5 \%$, Relative intensity of ARPs' peak was $>5 \%$.

TABLE-2

\begin{tabular}{|c|c|c|c|c|c|}
\hline \multicolumn{6}{|c|}{$\begin{array}{l}\text { TABLE-2 } \\
\text { MAIN FRAGMENTATION IONS AND INTENSITIES OF APRS IN MS }{ }^{2} \text { SPECTRA } \\
\text { OF GLYCATED AMINO ACIDS AND N-ACETYL-LYSINE WITH D-GLUCOSE }\end{array}$} \\
\hline Amino acid & ARPs & {$[\mathrm{M}+\mathrm{H}]^{+}(\mathrm{m} / \mathrm{z})$} & MS/MS peak & Loss & Fragments \\
\hline \multirow{5}{*}{ Arg } & \multirow{5}{*}{ Arg-Glc } & \multirow{4}{*}{$337.1(74 \%)$} & $319.2(100 \%)$ & -18 & $-\mathrm{H}_{2} \mathrm{O}$ \\
\hline & & & $303.0(23 \%)$ & -36 & $-2 \mathrm{H}_{2} \mathrm{O}$ \\
\hline & & & $283.1(5 \%)$ & -54 & $-3 \mathrm{H}_{2} \mathrm{O}$ \\
\hline & & & $175.2(24 \%)$ & -162 & $-\mathrm{C}_{6} \mathrm{H}_{10} \mathrm{O}_{5}$ \\
\hline & & \multirow{3}{*}{$295.0(42 \%)$} & $277.0(100 \%)$ & -18 & $-\mathrm{H}_{2} \mathrm{O}$ \\
\hline \multirow[t]{2}{*}{ Asn } & \multirow[t]{2}{*}{ Asn-Glc } & & $259.1(15 \%)$ & -36 & $-2 \mathrm{H}_{2} \mathrm{O}$ \\
\hline & & & $133.2(1 \%)$ & -162 & $-\mathrm{C}_{6} \mathrm{H}_{10} \mathrm{O}_{5}$ \\
\hline \multirow{4}{*}{ Gln } & \multirow{4}{*}{ Gln-Glc } & \multirow{4}{*}{$309.1(20 \%)$} & $291.1(100 \%)$ & -18 & $-\mathrm{H}_{2} \mathrm{O}$ \\
\hline & & & $273.1(15 \%)$ & -36 & $-2 \mathrm{H}_{2} \mathrm{O}$ \\
\hline & & & $225.2(1 \%)$ & -84 & $-3 \mathrm{H}_{2} \mathrm{O}-\mathrm{HCHO}$ \\
\hline & & & $147.1(1 \%)$ & -162 & $-\mathrm{C}_{6} \mathrm{H}_{10} \mathrm{O}_{5}$ \\
\hline \multirow{4}{*}{ His } & \multirow{4}{*}{ His-Glc } & \multirow{4}{*}{$318.1(45 \%)$} & $300.1(100 \%)$ & -18 & $-\mathrm{H}_{2} \mathrm{O}$ \\
\hline & & & $282.0(24 \%)$ & -36 & $-2 \mathrm{H}_{2} \mathrm{O}$ \\
\hline & & & $190.2(1 \%)$ & -128 & $-3 \mathrm{H}_{2} \mathrm{O}-\mathrm{HCHO}-\mathrm{CO}_{2}$ \\
\hline & & & $156.1(2 \%)$ & -162 & $-\mathrm{C}_{6} \mathrm{H}_{10} \mathrm{O}_{5}$ \\
\hline \multirow{5}{*}{ Lys } & \multirow{5}{*}{ Lys-Glc } & \multirow{5}{*}{$309.1(37 \%)$} & $291.1(100 \%)$ & -18 & $-\mathrm{H}_{2} \mathrm{O}$ \\
\hline & & & $273.1(18 \%)$ & -36 & $-2 \mathrm{H}_{2} \mathrm{O}$ \\
\hline & & & $255.2(1 \%)$ & -54 & $-3 \mathrm{H}_{2} \mathrm{O}$ \\
\hline & & & $225.2(5 \%)$ & -84 & $-3 \mathrm{H}_{2} \mathrm{O}-\mathrm{HCHO}$ \\
\hline & & & $147.1(4 \%)$ & -162 & $-\mathrm{C}_{6} \mathrm{H}_{10} \mathrm{O}_{5}$ \\
\hline \multirow{3}{*}{ Trp } & \multirow{3}{*}{ Trp-Glc } & \multirow{3}{*}{$367.137 \%)$} & $349.1(100 \%)$ & -18 & $-\mathrm{H}_{2} \mathrm{O}$ \\
\hline & & & $331.1(10 \%)$ & -36 & $-2 \mathrm{H}_{2} \mathrm{O}$ \\
\hline & & & $205.1(1 \%)$ & -162 & $-\mathrm{C}_{6} \mathrm{H}_{10} \mathrm{O}_{5}$ \\
\hline \multirow{5}{*}{ Ac-lys } & \multirow{5}{*}{ Ac-Lys-Glc } & \multirow{5}{*}{$351.1(40 \%)$} & $333.1(100 \%)$ & -18 & $-\mathrm{H}_{2} \mathrm{O}$ \\
\hline & & & $315.1(18 \%)$ & -36 & $-2 \mathrm{H}_{2} \mathrm{O}$ \\
\hline & & & $297.2(1 \%)$ & -54 & $-3 \mathrm{H}_{2} \mathrm{O}$ \\
\hline & & & $267.2(4 \%)$ & -84 & $3 \mathrm{H}_{2} \mathrm{O}-\mathrm{HCHO}$ \\
\hline & & & $189.2(4 \%)$ & -162 & $-\mathrm{C}_{6} \mathrm{H}_{10} \mathrm{O}_{5}$ \\
\hline
\end{tabular}

$[\mathrm{M}-54+\mathrm{H}]^{+},[\mathrm{M}-84+\mathrm{H}]^{+}$and $[\mathrm{M}-162+\mathrm{H}]^{+}$. The previous study reported that the 1-amino-1-deoxy-2-ketose (Enol form) was more stable by comparison with N-substituted glycosylamine, but still heat labile and decomposes rapidly under heating. In our study, data displayed that the dominant fragment ions correspond to the losses of 1-3 $\mathrm{H}_{2} \mathrm{O}$ molecules, one more formaldehyde $\mathrm{HCHO}$ molecule, forming oxonium ion and even sugar moiety as showing in Table- 2 .

It should be taken into account that although solutions of Amadori rearrangement products contain different forms, such as pyranose and furanose for glucose, it would produce [M-84
$+\mathrm{H}]^{+}$, or $[\mathrm{M}-246+\mathrm{H}]^{+}$in di-saccharide, like maltose. [M-84 $+\mathrm{H}]^{+} /[\mathrm{M}-246+\mathrm{H}]^{+}$in could be explained by the loss of a $\mathrm{HCHO}$ group and 3 water molecules in mono-saccharides and one more sugar moiety in di-saccharides to form a 5-membered ring of furylium ion ${ }^{17-20}$. Based on Amadori rearrangement products structures identified via $\mathrm{MS}^{2}$ in sugar-amino acid model system and results of theoretical calculation, the proposed fragmentation pathway of Amadori rearrangement products was summarized in Fig. 1.

Protonation sites of Amadori rearrangement products in ESI: In gas phase, the protonated molecules were more 


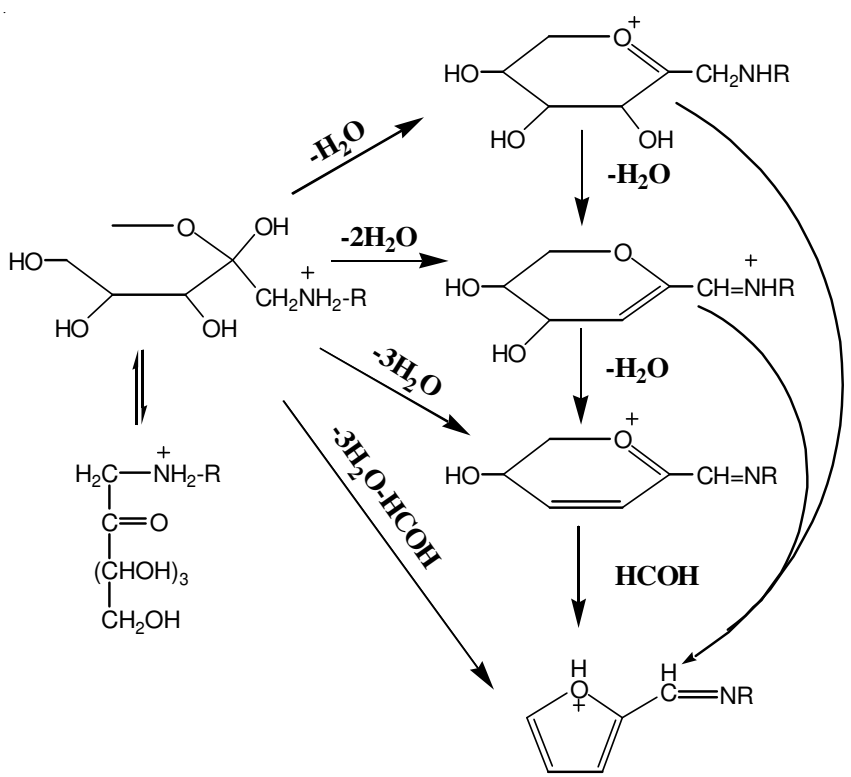

Fig. 1. Proposed fragmentation mechanism of sugar moiety of glucosederived Amadori rearrangement products for characteristic ions obtained by ESI-MS ${ }^{2}$

stable than free molecules and one or more protons could attach to the molecule to bestow charges on the analyte when ESI was used as an ion source. The sites on which the protons attached would critically determine the fragmentation type of the $[\mathrm{M}+\mathrm{H}]^{+}$ion. In order to understand the fragment patterns of Amadori rearrangement products in ESI-MS, DFT calculations on $[\mathrm{M}+\mathrm{H}]^{+}$ion with every possible protonation site were performed. During the calculation, K-bG-2 was used as the prototype as shown in Fig. 2. Four possible protonation sites, highlighted by circles, were examined, for example, the protonation site of $\mathrm{K}-\mathrm{bG}-2-\mathrm{H} 3$ was on the oxygen of the $\mathrm{C}-\mathrm{O}-\mathrm{C}$ group. When optimizing this structure, the proton of -OH group on the neighboring carbon automatically transferred to - NH group, followed by the cleavage of the $\mathrm{C}-\mathrm{O}$ bond and the formation of a carbonyl on the neighboring carbon.

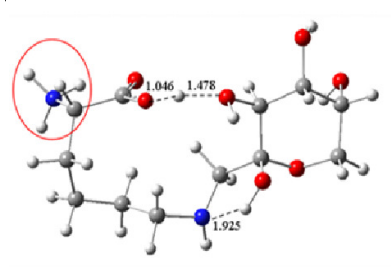

$\mathrm{K}-\mathrm{bG}-2-\mathrm{H} 1 \quad \Delta \mathrm{H}^{\circ}{ }_{0}=0.0 \mathrm{kcal} / \mathrm{mol}$

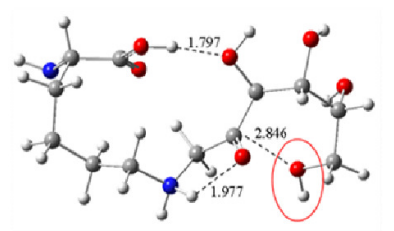

K-bG-2-H3 $\Delta \mathrm{H}_{0}^{\circ}=-2.4 \mathrm{kcal} / \mathrm{mo}$

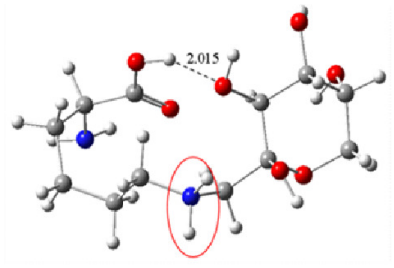

K-bG-2-H2 $\Delta \mathrm{H}_{0}^{\circ}=-1.7 \mathrm{kcal} / \mathrm{mol}$

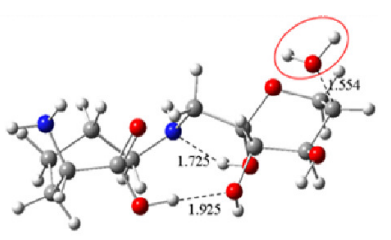

$\mathrm{K}-\mathrm{bG}-2-\mathrm{H} 4 \quad \Delta \mathrm{H}_{0}^{\circ}=28.9 \mathrm{kcal} / \mathrm{mol}$
Fig. 2. Geometries of the lowest-energy structures calculated at B3LYP/6$31++\mathrm{G}$ level for the products of lysine reacting with $\alpha-\mathrm{D}-$ glucopyranose and lysine reacting with $\beta$-D-glucopyranose respectively. K-aG-1 and K-bG-1 are products from reaction site of $\mathrm{N}$-terminus of lysine, $\mathrm{K}-\mathrm{aG}-2$ and $\mathrm{K}-\mathrm{bG}-2$ are products from reaction site of $\alpha-\mathrm{NH}_{2}$ of lysine. The bond lengths are in angstrom $(\AA)$
These changes rendered K-bG-2-H3 the lowest energy isomer of small energy difference $(0.7 \mathrm{kcal} / \mathrm{mol})$ where the -NH protonated K-bG-2, followed by K-bG-2-H2 with a group of K-bG-2 was protonated. The protonation on the -OH group of sugar ring formed the most energetically unfavorable isomer of $[\mathrm{M}+\mathrm{H}]^{+}(\mathrm{M}=\mathrm{K}-\mathrm{bG}-2)$. The two inter-convertible isomers corresponded to K-bG-2-H2 (closed-chain structure) and $\mathrm{K}-\mathrm{bG}-2-\mathrm{H} 3$ (open-chain structure). Starting from two coexisting isomers, the results supported the proposed fragmentation mechanism of sugar moiety of glucose-derived Amadori rearrangement products in $\mathrm{MS}^{2}$ experiments

\section{Conclusion}

The sugar-amino acid model used in the present study demonstrated the reaction temperature, reaction time, sugars and amino acid effects on forming APRs in the Maillard reaction. Besides $\alpha$-amino group of amino acids, the $\varepsilon$-amino group of lysine showed high reactivity. The fragmentation behaviors of the Amadori rearrangement products showed that the sugar moiety tended to be fragmented preferentially by neutral losses of water and/or formaldehyde molecules to form a relative stable oxonium ion, $[\mathrm{M}-84+\mathrm{H}]^{+}$in mono-saccharides and $[\mathrm{M}-246+\mathrm{H}]^{+}$in di-saccharide. Computational results were consistent with experimental observations, supporting the proposed Amadori rearrangement products fragmentation mechanism of glucosylated lysine. This provides the useful and fundamental information for complicated peptide and protein modification in Maillard reaction.

\section{ACKNOWLEDGEMENTS}

The authors thank Dr. T. Song, Department of Chemistry, University of Hong Kong, for his work of computational calculation and structural demonstration.

\section{REFERENCES}

1. L.C. Maillard, C.R. Acad. Sci. Ser. 2, 154, 66 (1912).

2. L.C. Maillard, C.R. Seances Soc. Biol. Paris, 72, 599 (1912).

3. J.E. Hodge, J. Agric. Food Chem., 1, 928 (1953).

4. J.E. Hodge and C.E. Rist, J. Am. Chem. Soc., 75, 316 (1953).

5. A. Abrams, P.H. Lowy and H. Borsook, J. Am. Chem. Soc., 77, 4794 (1955).

6. T. Davidek, F. Robert, S. Devaud, F.A. Vera and I. Blank, J. Agric. Food Chem., 54, 6677 (2006).

7. M. Roscic, C. Versluis, A.J. Kleinnijenhuis, S. Horvat and A.J. Heck, Rapid Commun. Mass Spectrom., 15, 1002 (2001).

8. P.J. Thornalley, Ann. N. Y. Acad. Sci., 1043, 111 (2005).

9. M.C. Thomas, J.W. Baynes, S.R. Thorpe and M.E. Cooper, Curr. Drug Targets, 6, 453 (2005).

10. O. Novotny, K. Cejpek and J. Velisek, Czech. J. Food Sci., 25, 119 (2007).

11. F. Robert, F.A. Vera, F. Kervella, T. Davidek and I. Blank, Ann. N. Y. Acad. Sci., 1043, 63 (2005).

12. A. Frolov, P. Hoffmann and R. Hoffmann, J. Mass Spectrom., 41, 1459 (2006).

13. L.B. Fay and H. Brevard, Mass Spectrom. Rev., 24, 487 (2005).

14. T. Yalcin and A.G. Harrison, J. Mass Spectrom., 31, 1237 (1996).

15. A.D. Becke, Chem. Phys., 98, 5648 (1993).

16. T. Clark, J. Chandrasekhar, G.W. Spitznagel and P.R. Schleyer, J. Comput. Chem., 4, 294 (1983).

17. V.F. Taylor, R.E. March, H.P. Longerich and C.J. Stadey, Int. J. Mass Spectrom., 243, 71 (2005).

18. S. Horvat and A. Jakas, J. Pept. Sci., 10, 119 (2004).

19. A. Jakas, A. Katic, N. Bionda and S. Horvat, Carbohydr. Res., 343, 2475 (2008).

20. I. Jeric, C. Versluis, S. Horvat and A.J.R. Heck, J. Mass Spectrom., 37, (2002). 